\title{
Case Study: Expression of Two Near Absent Dental Traits, Lingual Cuspule and Paraconid, on One Archaic Period Modern Human from the Ohio Valley
}

\author{
Erin C. Blankenship-Sefczek* \\ The Ohio State University, USA
}

Keywords: Dental variation, dental evolution, rare trait

ABSTRACT Dental anomalies in modern humans are used to discuss biological variation and evolutionary changes. Presented here are the lingual cuspule and paraconid; two traits considered near absent (occurring $<1 \%$ ) in world populations. The only other example of a lingual cuspule comes from an African population. The paraconid was thought to have been lost in primate evolution starting in the Oligocene (34-23 MYA). Both traits were found on the lower third molars of a male individual from the late Archaic (2500-500 BC) site of Shick in Handcock County, Ohio. Here the lingual cuspule is present unilaterally on the right third molar, whereas the other reported case shows the trait being expressed bilaterally on the first molars. Therefore, the lingual cuspule can be found on molars across the row. Additionally, each example exhibits a fully developed cuspule with a free apex. These data indicate the lingual cuspule could be incorporated into studies of biodistance and morphological variation. Contextualizing the paraconid is more challenging given that the only reported examples of this trait in extant primates come from the tarsier. The expression of a paraconid in modern humans could suggest secondary evolution of this trait. Further reporting of both the lingual cuspule and paraconid are necessary to better understand these traits and discuss their importance in modern human variation.

Over the course of human evolution there is a simplification in the expression of tooth traits (i.e. a reduction in cusp number, and occlusal ridges; Bailey and Hublin, 2013); however, there still exists considerable variation in the expression of dental morphology in world populations (Turner et al., 1991; Scott and Turner, 1997; Hanihara, 2008; Scott et al., 2016; Irish, 2016). Placement of tooth cusps, both principal and accessory, can be used to discuss morphological variation. Generally, accessory cusps are initiated after the principal cusps have formed (Kraus and Jordan, 1965; Hillson 1996) making their expression more variable and less frequent than principal cusps. While many mandibular paramolar structures, such as the Mandibular Molar Pit -Tubercle (MMTP; Weets, 2009) and protostylid (Dahlberg, 1950), have been identified and described in several populations, there are several traits that are less common. For example, odontomes on premolars, the mesial canine ridge (Scott and Turner, 1997), and the labial talon cusp on incisors (Stojanowski and Johnson, 2011) are much less common traits within a given population. Traits that are found in $4-7 \%$ of a population are considered "rare"; "very rare" traits are found in $1-3 \%$ of a population, and "near absent" when they are found in less than 1\% of a population (Scott and Turner 1997: 191, 193). Assessing patterns of dental trait expressions are useful to understand biological variation, migration of modern human populations around the world (Scott and Turner, 1997; Hanihara, 2013; Scott et al., 2018), and evolutionary changes within and between hominin taxa (Bailey and Hublin, 2013; Martinon-Torres et al., 2013; Guatelli-Steinberg 2016).

The goals of this paper are to 1) describe two rare lower molar traits, the lingual cuspule (Irish, 1991) and the paraconid, and 2) contextualize them in modern human variation. Only one other study has identified the lingual cuspule, which was observed on a single individual (Irish, 1991). The paraconid is a principle cusp which has been identified in early primate ancestors, but appears to have been lost, with the exception of tarsiers, before the emergence of hominins (Gregory, 1922; Ankel-Simons, 2007; Fleagle, 2013). To date, no studies have reported this cusp in modern humans. Both the lingual cuspule and the paraconid were observed on mandibular third molars of a single individual from the Archaic period (2500-500 BC) in the Ohio Valley. Neither of these dental anomalies has been extensively documented in modern humans, and both may be considered near absent in world populations. It is possible that these molar cusps are simply over-

\section{*Correspondence to:}

Erin C. Blankenship-Sefczek

Department of Anthropology

The Ohio State University

blankenship-sefczek.1@osu.edu 
looked, in which case studies should highlight them, or that they are misinterpreted, which would indicate new methods should be used to amend recording procedures.

\section{Materials and Methods}

This study was conducted on human skeletal remains from the Archaic Period in the Ohio Valley. The individual presented in this paper was found at the Shick site located in Mount Cory, Handcock County, Ohio occupied between 2500-500 BC. The skeletal collections are housed at the Ohio History Connection in Columbus, Ohio. The Shick site settlements during the Archaic period were considered "sizable" compared to earlier periods, and were occupied on a seasonal basis (Sciulli and Oberly 2002). Late Archaic communities practiced a hunting and gathering subsistence (Sciulli and Oberly 2002).

Fourty-eight individuals from the Late Archaic period were examined. Tooth traits for all individuals were recorded using the Arizona State University Dental Anthropology System (ASUDAS; Turner et al. 1991). Reference manuals, recent publications (Scott and Turner, 1997; Weets, 2009; Marado and Silva, 2016; Scott et al., 2016; Scott and Irish, 2017), and consultation with Joel Irish were used to identify these traits as neither the lingual cuspule nor paraconid are included in the ASUDAS. Based on information from available sources, the descriptions presented below were used to identify the two cusps.

The lingual cuspule is described as a "triangularshaped structure" located on the disto-lingual enamel surface, not associated with the metaconulid (cusp 7), and similar in form, though not in location, to the protostylid (found on the buccal surface; Irish, 1991:2). Originating at the cemento-enamel junction just distal on the metaconid, the lingual cuspule is not an occlusal trait (Irish, 1991), but a rather is a peripheral accessory cusp.

Taking up the mesial portion of the trigonid of lower molars, the paraconid is described as a principal cusp located most anterior and mesiolingually to the other lower molar cusps (Gregory, 1922; Ankel-Simons, 2007; Fleagle, 2013). The paraconid is noted as being an archaic primate feature that reduces in size and disappears altogether by the Oligocene (Gregory, 1922; Simons, 1989; Ankel-Simons, 2007; Fleagle, 2013). The tarsier is the only reported example of a modern primate to have retained the paraconid (Swindler, 2002; Ankel-Simons, 2007).

\section{Results}

Of the 48 individuals observed from the Late Archaic sample, only one was found to have either a lingual cuspule or a paraconid (A4489-6). The lingual cuspule was observed on this individual's mandibular right third molar and the anterior cusp (paraconid) was expressed bilaterally. While the lingual cuspule and the paraconid are the two cusps of interest in this paper, individuals in the Late Archaic sample exhibited a variety of other lower molar traits including low-grade expressions of the protostylid $(n=20)$, fully developed cusp $6(n=11)$, large cusp $7(n=1)$, deep anterior fovea $(n=8)$, and defined deflecting wrinkle $(n=4)$. In addition to the lingual cuspule and the paraconid, the individual presented here also exhibited a low-grade expression of the protostylid (pit in the buccal groove; Turner et al., 1991) on all lower molars as well as a bifurcated hypoconulid on the lower right third molar. The upper molars of this individual exhibit a reduction in size of the hypocone from the first to third molars on both sides.

\section{Lingual Cuspule}

The lower right third molar of this individual exhibits a large, fully developed cuspule located mesially on the lingual surface of both the paraconid and metaconid of a right third molar (Figure 1, arrow 1). The lingual cuspule is nearly equal in size to the protoconid, metaconid, and paraconid. The tooth appears to have been rotated buccally such that the paraconid is oriented toward the buccal aspect of the mandible, rather than to the distal portion of M2; the orientation brings the lingual cuspule into contact with the hypoconulid of M2.

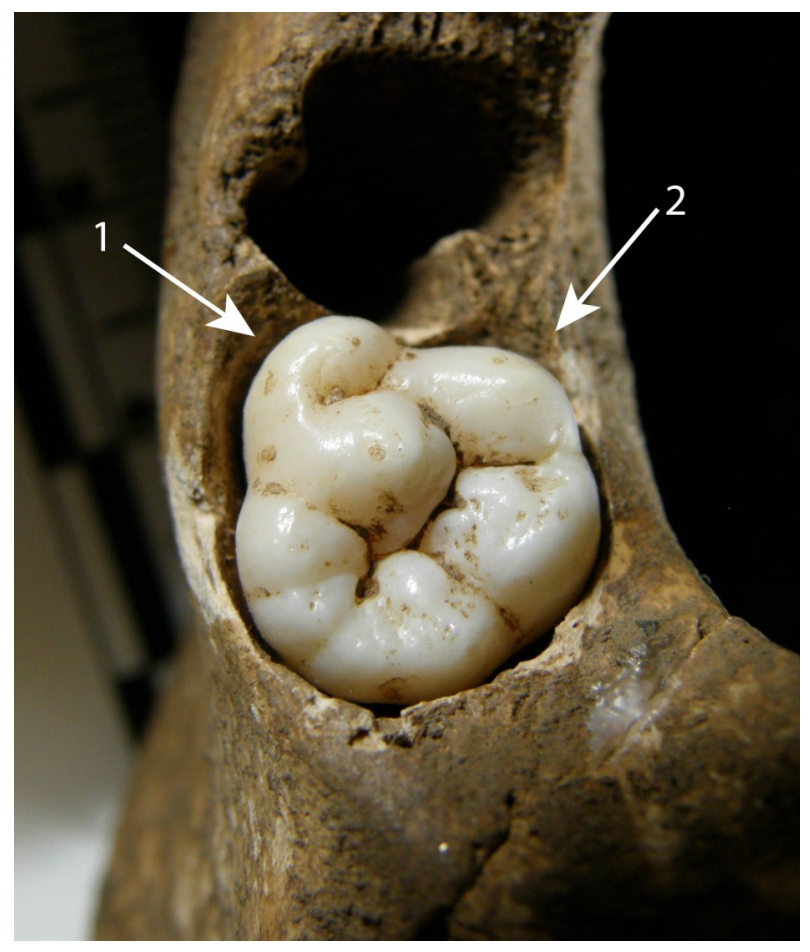

Figure 1. Lower right third molar from burial A4489-6 (Archaic period; Mt. Cory Ohio, Handcock County) with a fully developed lingual cuspule (arrow 1) and paraconid (arrow 2). 


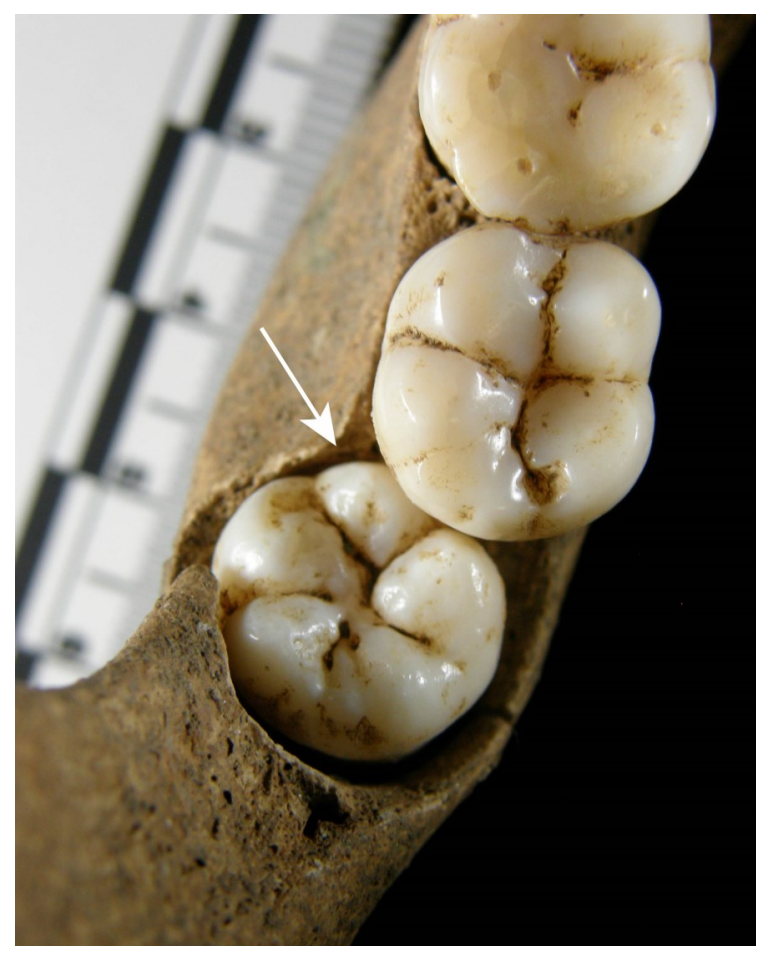

Figure 2. Lower left third molar from burial A4489-6 (Archaic period; Mt. Cory Ohio, Handcock County) with a fully developed paraconid (white arrow).

\section{Paraconid}

On the right and left third molar, this individual possesses a cusp in the location where, by definition (Gregory, 1922; Ankel-Simons, 2007; Fleagle, 2013) the paraconid develops. In both expressions, a fully developed mesial cusp with a free apex is present (Figure 1, arrow 2 and Figure 2). The cusp appears to originate at the cemento-enamel junction between the protoconid and metaconid. The root exhibits a seamless transition with the enamel suggesting the cusp was formed along with other principal cusps during the initial down-folding of the enamel epithelium (Jernvall and Thesleff, 2000) and is not a peripheral accessory cusp. The cusp is equal in size to the protoconid and metaconid.

\section{Discussion}

Based on the available literature, it appears that the lingual cuspule and the paraconid are near absent traits in modern human populations. While more information is needed about both traits to complete a more in depth discussion on how they might inform on studies of migration, or biodistance, it is possible to demonstrate their eventual usefulness in these applications.

Scott (2008) identifies a set of criteria, or principles, to use when including a new trait into studies of bio- distance. These criteria begin with 1) the presence of a distinct trait, 2) a consistent expression of the trait within the same tooth type, and 3) examination of multiple diverse populations for presence of the trait. After these steps have been satisfied, there can be a more in-depth analysis of the trait wherein a scoring system is developed (Scott, 2008). Both the lingual cuspule and the paraconid satisfy the first criteria of being distinct traits. With the inclusion of other sources, a discussion of criterion two and three is possible for the lingual cuspule, and will be undertaken below. Given the lack of paraconid examples in modern humans, contextualizing this trait within Scott's (2008) criterion cannot be done here. The paraconid can, however, be discussed in an evolutionary context.

\section{Lingual cuspule}

Scott's (2008) second criteria requires that the trait in question be consistently expressed within the same tooth type. Regarding the lingual cuspule, the only other reported case was found bilaterally on both the left and right lower first molars of a male individual (Irish, 1991). The cuspule is noted to be a triangular shape with a free apex, and located on the distolingual surface just distal to a small metaconulid (Irish, 1991). The individual presented in the current study possesses a unilateral expression of the lingual cuspule found on the lower right third molar of a male individual. This expression of the trait is larger, more bulbus at the apex, and more mesially placed than the example described by Irish (1991). An example of what here is called the lingual cuspule may also be present on the lower left third molar of a female individual but is recorded there as an expression of the MMTP (Marado, 2014: 236). The MMTP is expressed as an ident, pit, or fully developed cusp high on the buccal surface of the protocone (Weets, 2009; Marado and Silva, 2016) whereas the lingual cuspule has been identified as a fully developed cusp found on the lingual surface of the crown. The examples presented here suggest this trait's expression is consistently found on first and third mandibular molars from both the left and right sides.

The third criteria on Scott's (2008) list necessitates the observation of the trait in question across multiple distinct populations. The lingual cuspule has been reported in one individual from the Bantu-speaking Central Sotho from South Africa (Irish, 1991). The individual presented in the current study is from a Native American population in the Ohio Valley. The possible third example, discussed above, comes from a Portuguese population (Marado, 2014). Additionally, Joel Irish (1991: 2-3) recalls A. Dahlberg observing the lingual cuspule once before in a Native American population, though no additional information on this 
example is included. Therefore, at present the lingual cuspule has been identified in two populations, South African and Native American, with the possibly if its occurrence in a third, Portuguese. Lack of reporting on the lingual cuspule may be because the trait is being conflated with other paramolar structures, such as the MMTP. Although the MMTP is described as occurring on the buccal surface of mandibular molars (Weets, 2009; Marado and Silva, 2016), it is possible that similar expressions on the lingual surface are being lumped together during observation and recording since no formal scoring is in place for lingual expressions.

\section{Paraconid}

While the paraconid is a distinct trait, there are no other examples of its expression in modern human populations; therefore, determining a consistent expression within a tooth type, or addressing its prevalence within multiple world populations cannot be attempted here. However, a discussion of paraconid evolution and contextualizing this trait within human dental variation may be more informative.

First seen in the Mesozoic era, the paraconid is a mandibular principal cusp located on the mesial border between the protoconid and metaconid, as part of the trigonid (Gregory, 1922; Ungar 2017). The gradual reduction, and then complete loss of the paraconid in primate evolution is contemporaneous with the appearance of the upper molar hypocone (Gregory, 1922). By the middle Eocene, Notharctus (an extinct form of North American Adapoidea) exhibits a paraconid of reduced size (Gregory, 1922; Fleagle, 2013). Parapithecids in the Oligocene have lost the paraconid altogether, resulting in an absence of this trait in modern Cercopithecidae (Gregory, 1922; Ankel-Simons, 2007). Although this does not directly speak to hominins and modern humans, based on the lack of acknowledgement in the literature, including a recent review of evolutionary changes associated with hominin and modern human dentition (Guatelli-Steinberg, 2016), the paraconid appears to have been absent in hominin evolution as well (pers. com. Joel Irish). Because only one individual of the fourty-eight within the study population expresses the paraconid, occurrence within this group can be considered near absent.

Despite being lost prior to hominin emergence, a cusp that is likely a paraconid is present in a modern human dental arcade. This expression could suggest that humans have not completely lost the ability to express a paraconid. However, the retained ability to develop a paraconid does not seem likely since this cusp was lost with the Parapithecids (Gregory, 1922) and has only been documented in tarsiers since the Oligocene (Swindler, 2002; Ankel-Simons, 2007). Al- ternatively, it is possible that the presence of a paraconid in a modern human is an example of a secondarily derived trait. Although it is not common for traits to reappear once lost, there are examples in the dentition where this has occurred (Lipson and Pilbean, 1982; Luo et al., 2004). If other modern human populations also exhibit a remnant paraconid, the discussion could lead to valuable insights into the recent evolution of hominin dentition.

\section{Conclusions}

Both the lingual cuspule and the paraconid appear to be rare, if not near absent, traits in modern human populations. Based on the data presented here, the lingual cuspule has the potential to satisfy the criteria set by Scott (2008) and be included in studies of dental morphology and biodistance. If more examples of this trait can be identified, a scoring system could be determined, allowing the lingual cuspule to act as an additional source of information in understanding modern human dental variation. It is currently unclear whether or not the paraconid could be included in biodistance studies as the example presented here is the only one reported in modern humans. Looking at this trait from an evolutionary approach, the presence of a paraconid on a modern human tooth could represent an example of a secondarily derived trait. Additional examples from a variety of populations are necessary to further discuss what information these two traits could offer in studies of human teeth.

\section{Acknowledgments}

These findings are part of a research project funded by the Ohio State University Alumni Grant for Graduate Research and Scholarship, and the Larsen Research and Travel Award. I wish to thank Ohio History Connection for allowing me to conduct research on their collections, and permission to use photographs of dentition. Special thanks are given to Joel Irish for consulting on this "weird" tooth. Thank you to Tim Sefczek for reading drafts of this manuscript. Lastly, I thank editors and reviewers of the Dental Anthropology Journal for their comments on this manuscript.

\section{REFERENCES}

Ankel-Simons, F. 2007. Primate Anatomy: An Introduction. Elsevier, Academic Press: Oxford.

Fleagle, J.G. 2013. Primate Adaptation \& Evolution. Elsevier, Academic Press: London.

Guatelli-Steinberg, D. 2016. What Teeth Reveal about Human Evolution. Cambridge University Press: Cambridge.

Gregory, W.K. 1922. Origin and Evolution of the Human Dentition. Williams \& Wilkins Company: Baltimore. 
Hanihara, T. 2008. Morphological variation of major human populations based on nonmetric dental traits. American Journal of Physical Anthropology 136:169-182.

Hillson, S. 1996. Dental Anthropology. Cambridge University Press: Cambridge.

Irish, J.D. 1991. LM1 Lingual Cuspule in a Central Sotho dentition from South Africa. Dental Anthropology Journal 5(2): 2-3.

Jernvall, J. \& Thesleff, I. 2000. Reiterative signaling and patterning during mammalian tooth morphogenesis. Mechanisms of Development 92: 19-29.

Kraus, B.S. \& Jordan., R.J. 1965. The Human Dentition Before Birth. Lea and Febiger: Philidelphia.

Lipson, S., \& Pilbeam, D. 1982. Ramapithecus and Hominoid Evolution. Journal of Human Evolution 11: 545548.

Luo, Z., Kielan-Jaworowska, Z. \& Cifelli, R.L. 2004. Evolution of dental replacement in mammals. Bulletin of the Carnegie Museum of Natural History 36: 159175.

Marado, L.M. 2014. Characterization of the dental morphology of a Portuguese sample from the $19^{\text {th }}$ and $20^{\text {th }}$ Centuries. Dissertation, University of Coimbra.

Marado, L.M. \& Silva, A.M. 2016. The mandibular molar pit-tubercle (MMTP) dental nonmetric trait: Comprehensive analysis of a large sample. HOMOJournal of Comparative Human Biology 67: 462-470.

Martinon-Torres, M., Bermudez de Castro, J.M., Martin -Frances, L,. Garcia-Tellez, A., Martinez, I., \& Arsuaga, J.L. 2013. Dental morphology of European Middle Pleistocene populations. In Anthropological Perspecitives on Tooth Morphology: Genetics, Evolution, Variation. G Richard Scott and Joel D Irish, eds. Pp: 201-221. Cambridge University Press: Cambridge.

Salazar-Ciudad I., \& Jernvall, J. 2002. A gene network model accounting for development and evolution of mammalian teeth. Proceedings of the National Academy of Science 99: 8116-8120.

Scott, G.R., Schmitz, K., Heim, K.N., Paul, K.S., Schomberg, R., \& Pilloud, M.A. 2018. Sinodonty, Sunadonty, and the Beringian Standstill model: Issues of timing and migration into the New World. Quarterly International 466: 233-246.

Scott, GR, \& Irish, J.D. 2017. Human Tooth Crown and Root Morphology: The Arizona State University Dental Anthropology System. Cambridge University Press: Cambridge.

Scott, GR, Maier, C. \& Heim, K. 2016. Identifying and recording key morphological (nonmetric) crown and root traits. In A Companion to Dental Anthropology. JD Irish and GR Scott, eds. Pp 247-264. Wiley Blackwell: Oxford.

Scott, G.R. 2008. Dental Morphology. In Biological Anthropology of the Human Skeleton. M. Katzenberg A and Saunders SR (eds.). Willey-Liss, Inc

Scott, G.R. \& Turner, C.G. 1997. The Anthropology of Modern Human Teeth: Dental Morphology and its Variation in Recent Human Populations. Cambridge University Press: Cambridge.

Simons, E.L. 1989. Description of two genera and species of Late Eocene Anthropoidea from Egypt. Proceedings of the National Academy of Science 86: 99569960.

Stojanowski, C.M. \& Johnson, K.M. 2011. Labial talon cusp from the Early Holocene site of Gobero, Central Sahara Desert, Niger. International Journal of Osteoarchaeology 21: 391-406.

Swindler, D.R. 2002. Primate Dentition: An Introduction to the Teeth of Non-human Primates. Cambridge University Press: Cambridge

Turner, C.G., Nichol, C.R., \& Scott, G.R. 1991. Scoring procedures for key morphological traits of the permanent dentition: the Arizona State University dental anthropology system. In Advances in Dental Anthropology. Kelley MA and CS Larsen, eds. Pp: 13-31. John Wiley: New York

Ungar, P.S. 2016. Origins and Functions of Teeth: From "Toothed" Worms to Mammals. In A Companion to Dental Anthropology. Irish JD and Scott GR (eds.). Wiley Blackwell: Oxford.

Weets, J.D. 2009. A promising mandibular molar trait in ancient populations of Ireland. Dental Anthropology Journal 22(3): 65-72 